\title{
Free Digital Learning for Inclusion of Migrants and Refugees in Europe: A Qualitative Analysis of Three Types of Learning Purposes
}

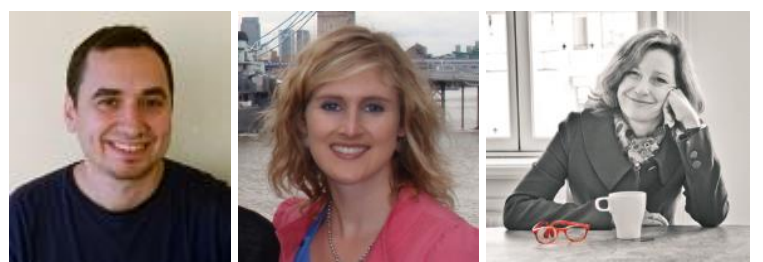

Jonatan Castaño Muñoz ${ }^{1}$, Elizabeth Colucci ${ }^{2}$, and Hanne Smidt ${ }^{3}$

${ }^{1}$ Joint Research Centre, European Commission', Seville, Spain, ${ }^{2}$ International Policy Advisor, European University

Association, Seville, Spain, ${ }^{3}$ Senior Advisor European University Association, Stockholm, Sweden

\begin{abstract}
The increasing number of migrants and refugees arriving in Europe places new demands on European education systems. In this context, the role that free digital learning (FDL) could play in fostering inclusion has attracted renewed interest. While the existing literature highlights some general design principles for developing FDL for migrants and refugees, there is little information on the use of FDL at specific education levels, or for specific learning purposes. This paper presents the results of a qualitative study that was carried out as part of the Moocs4Inclusion project of the Joint Research Centre (JRC) between July and December 2016. The study, which has a European focus, disaggregates the analysis of FDL initiatives by what were identified as its three most common purposes: a) language learning, b) civic integration and employment, and c) higher education. For each of these topics, the study sheds light on the approaches used by a wide sample of initiatives, users' levels of awareness of what is available and take up, and migrants' and refugees' perceptions of the current offer. In order to collect the information needed to cover different approaches and perspectives, semistructured interviews with 24 representatives of 10 FDL initiatives and four focus groups with 39 migrants and refugees were carried out. The results show that there are indeed overlaps between the purposes of FDL initiatives and their design principles. Specific recommendations on how to better design FDL initiatives for migrants and refugees, taking into account their specific purposes, have also been identified.
\end{abstract}

Keywords: free digital learning, MOOCs, open education, migrants, refugees, Europe, higher education, language learning, civic integration, employment 


\section{Introduction}

European countries are being asked to support the integration of third-country migrants (non-EU nationals) much more than they did in the past. In 2015, the number of asylum applications in Europe reached 1.3 million, three times what it was in 2013 and twice what it was in 2014. These numbers have diminished somewhat recently, due to increased control imposed by the EU Member States. According to Eurostat, the number of first-time asylum applicants decreased by $51 \%$ in the fourth quarter of 2016 compared with the same quarter of 2015 and by $43 \%$ compared with the third quarter of 2016 (Eurostat, 2017). However, the question of how to provide knowledge, information, and education that can support the integration of those who are arriving or are already in Europe, remains a glaring priority.

In 2015, 10.1\% of the individuals born in the EU were not in education, employment, or training. This figure was $19.8 \%$ for individuals between 15 and 29 years old who were not born in the EU but were living in it (Eurostat, 2016). In addition, young (18-24) non-EU citizens are at greater risk of becoming school dropouts than young EU citizens (Eurostat, 2016). On the other hand, adult migrants seem to participate more in less formal types of education: individuals between 25-54 years old, born outside of the EU, tend to participate more in lifelong learning activities than individuals of the same age living in the EU Member State they were born in (Eurostat, 2016). Only 50\% of refugees worldwide have access to primary education, compared with an overall access level of more than $90 \%$, and only $1 \%$ of refugees are enrolled in higher education (HE; The United Nations High Commissioner for Refugees [UNHCR] 2016). Information on refugee enrolment in formal education at EU level is patchy; though the situation may be better than the one reflected by UN figures (which primarily refer to refugees in camps outside Europe), there are huge challenges to ensure the integration of the very diverse migrant population. For example, according to an NGO study, refugee children remain out of school for 1.5 years on average after arriving in Greece, a country receiving high numbers of refugees (Save the Children, 2017).

Various studies have found that learning is critical for migrant inclusion (Schneeweis, 2011; Nonchev \& Targarov, 2012; Organisation for Economic Co-operation and Development (OECD), 2015; De Paola \& Brunello, 2016). Subsequently, the importance of providing education for migrants and refugees has been recognised by governments and national and international organisations. A document accompanying the New Skills Agenda for Europe recognises the need for adequate migrant and refugee education. This document states that "besides meeting refugees" most urgent needs, such as accommodation and food, there is a need to help improve their long-term situation, including by helping them to quickly improve their skills in the language of their host countries, in order to integrate into society, and to find employment" (European Commission, 2016a, p. 17). This vision goes beyond access to formal education, and recognition of prior learning, and also recognises the importance of less formal types of education.

In this context, the role that digital learning could play in widening access to education, developing the skills and knowledge needed by migrants and refugees in host countries (and further afield), and in fostering inclusion has attracted renewed interest. Digital means are seen as cost-effective and flexible solutions that could be scaled up to provide learning opportunities to migrants and refugees. The UNHCR (2016), for example, is increasingly considering e-learning to be an important way to bring flexible learning to refugees, particularly in refugee camps. It also recognises that the use of technology and the internet is not restricted to tertiary education and is useful for developing skills 
and competences that can be immediately useful in the host country. Along the same lines, the European Commission specifically mentions the use of technological advancements, such as the internet, smartphones, and interactive learning, as valuable tools to make integration and learning easier in its 2016 Communication Lives in Dignity: From Aid-Dependence to Self-Reliance (European Commission, 2016b). In parallel, a plethora of initiatives are flourishing, both bottom-up and government/donor supported, and engaging different stakeholders (see Moocs4Inclusion homepage for an overview of initiatives in Europe).

However, despite digital learning's potential, research has found that the use of some types of digital learning, such as Massive Open Online Courses (MOOCs), by vulnerable groups (including migrants and refugees) and less educated individuals, is lower than expected Liyanagunawardena, Adams, \& Williams, 2013; Glass, Shiokawa-Baklan, \& Saltarelli, 2016). When it comes to the use of digital learning by economically underprivileged populations, the existence of cost-free materials, courses, and learning opportunities for learners is extremely important (Lewis \& Thacker, 2016). But the fact that an online learning resource is free is not enough: instructional design principles and support services play an important role

\section{Key Design Principles for FDL for Migrants and Refugees}

The use of free digital learning, specifically for migrant and refugee education, is a new field and there is little research that assesses its take-up and impact. There are, however, some academic reports that provide design and delivery principles for digital learning content targeted at this population.

Guided instruction: Self-directed learning and digital skills are recognised as two important components for participation in digital learning (Song \& Hill, 2007; Jansen, Janssen, Kester, \& Kalz, 2017; Castaño Muñoz, Kreijns Kalz, \& Punie, 2017). However, literature signals that migrants and refugees may require additional guidance in the usage of digital learning sources, due to the fact that certain cultural learning traditions and skills may differ from the traditional online learner, and their stressful situation might impede their learning. Mason and Buchmann (2016) suggest that an outreach plan and support structures (vs self-learning) are essential when targeting migrants and refugees with FDL initiatives. Colucci et al. (2017) show that migrants and refugees prefer approaches which are tailored to their specific needs and characteristics, and include support mechanisms. These approaches are also in line with the UNHCR's recommendations for delivering education in crisis and conflict situations (UNHCR, 2016). Finally, Lewis and Thacker (2016) signal the usefulness of technology, not only for developing learners' skills, but also for promoting support structures to guided-learning, for example using ICT for teacher training or helping relief organisations.

Personalized learning: Personalized learning, as a type of instruction focused on meeting students' individual learning needs and preferences, has been signalled as promising strategy for increasing academic performance (Pane, Steiner, Baird, Hamilton, \& Pane, 2017). Migrants and refugee learners are a more heterogeneous target group than traditional learners and several studies highlight the importance of understanding their learning needs and capabilities (De Waard et al., 2014; Lewis \& Thacker, 2016). Mason and Buchmann (2016) identify various factors that affect learning initiatives in the context of the refugee crisis, which have to be taken into consideration when designing digital learning for refugees. These factors include the number of refugees, their different backgrounds, their previous education, where they are located, their literacy and language skills, whether their studies were interrupted, and any traumatic experiences they may have had. From an "education in emergencies" perspective, Moser-Mercer (2014) also argues that in higher education it is important to 
tailor learning activities to the needs of the concrete target audience, taking into account their existing skills, the learning environment and their learning culture. The same authors (Moser-Mercer, Hayba, \& Goldsmith, 2016) conclude that "human-centred" design is central to both pedagogical and technological development in fragile contexts and that ideally learning should be designed following a bottom-up approach that involves the learners.

Blended learning contexts. Social networks are valuable tools for finding and sharing resources, and facilitate migrants' participation in the society (Poros, 2008), labour market (Kahanec \& Mendola, 2007), and education (Calvó-Armengol Patacchini, \& Zenou, 2008) of the host-country. However, while $100 \%$ online learning can be a useful way to transmit knowledge, it is less clear if it is appropriate for developing contact and personal connections, especially when it comes to large courses such as MOOCs (Toven-Lindset, Rhoads \& Lozan, 2015) Consequently, despite the possibilities of online interaction (Castaño-Muñoz, Duart, \& Sancho-Vinuesa, 2013 ), migrants and refugees may need more face-to-face contact than traditional students. Moreover, face-to-face learning may be useful to build a higher sense of community, which is associated to higher satisfaction with and persistence in online learning (Rovai, 2002).

Blended learning is considered a cost-effective delivery mode for education (Escueta, Quan, Nickow , \& Orepoulos, 2017) that may benefit from the best of the online and face-to-face learning. Literature recognises peers and teachers as components of the personal network of migrants and refugees, and recommends that digital learning for these groups should accompany and supplement but not replace on-site interaction, support, or tutoring. Mason and Buchmann (2016) affirm that while standalone digital offers, like MOOC platforms or other online courses, are valuable resources, they rarely reach and enable migrant and refugee learners as such. UNHCR (2016), Dahya (2016), Lewis and Thacker (2016), and Colucci et al. (2017), also argue for blended learning approaches. These studies consider that digital resources should not (and cannot) replace face-to-face teaching, especially if the former does not ensure formal and reliable certification that may help to the transition into the labour market or formal education.

\section{Objective}

Most of the papers and reports quoted above deal with general design principles for digital learning initiatives for migrants and refugees. Some have focused specifically on conflict situations and refugee education in camps, for example. However, few of them have differentiated between specific types of digital learning for specific education levels or for specific learning purposes. In order to contribute new knowledge, we conducted a qualitative study of migrants/refugee learners and FDL providers, where we disaggregated the analysis according to three primary purposes. These purposes had been previously identified as those for which the development of FDL initiatives and resources for integration, and inclusion of migrants and refugees had been most intensive (Colucci et al., 2017): obtaining a higher education degree, language learning, and civic integration and employment.

We purposely excluded from the analysis digital learning that requires payment by learners. For the purposes of this study, we focused on free digital learning (FDL) defined as follows:

all learning activities (formal - leading to a degree or certification, informal and non-formal) at all education levels, undertaken with the support of ICT tools (e.g. computers, tablets, mobile phones, apps, used online or offline) at no (or very low) cost to the learner, barring potential additional costs for validating or certifying the learning or other extra services. This 
would include online courses such as MOOCs, offered in a stand-alone manner or in the context of a targeted migrant/refugee learning initiative, online or downloaded language courses, apps that provide learning opportunities, digital games with an explicit learning purposes and other online learning content directed at migrant/refugee inclusion and integration in their host societies and future job markets. (Colucci et al., 2017, p. 10)

The aim of the study is to highlight transversal approaches, problems, and success factors' but also identify the specificities for each type of learning purpose under analysis. For this, the guiding research questions are as follows:

- RQ1: What are the approaches taken by various FDL initiatives for migrants and refugee in Europe? Do they vary by learning purpose?

- RQ2: What are the current awareness and take-up of current FDL initiatives by migrants and refugees in Europe? Does it vary by learning purpose?

- RQ3: What are the learners' perceptions of the effectiveness of current FDL initiatives aimed to migrants and refugees in Europe? Do they vary by learning purpose?

\section{Methods}

The data for this paper comes from the Moocs4Inclusion project conducted in the second half of 2016 (Colucci et al., 2017). The Moocs4Inclusion project used a combination of research methods: literature review, compiling a catalogue of FDL initiatives (http://moocs4inclusion.org/index.php/catalogue) for migrants and refugees, and qualitative techniques (interviews with providers of FDL and focus groups of migrants and refugees). The use of qualitative techniques was based on a constructivist paradigm, which was considered adequate due to the novelty of the topic and the fact that our aim was to understand the meaning that different groups (migrants, refugees, and FDL providers) ascribe to FDL. Moreover, our research intended to have a transformative nature rather than build a new theory; it aims to generate knowledge that could be used to better adapt different types of FDL to the current needs and preferences of the learners.

This paper presents a refined analysis of the primary qualitative data collected during the project, notably from the interviews and focus groups. In order to give a more comprehensive view of the phenomenon under study, the qualitative part of study brought together the perspective of learners and the perspective of those designing and managing FDL initiatives. Information from the initiatives was especially useful for responding RQ1 and RQ2 and information from the learners for RQ2 and RQ3. The analysis is complemented with results from a literature review and the catalogue of initiatives which provide useful information to respond to RQ1.

The inclusion of a variety and diversity of learners and initiatives in the research allowed us to analyse the data in a disaggregated way. This approximation allowed us to obtain a panoramic vision of the perceptions and use of FDL by migrants and refugees in Europe for different purposes, as well as the opportunities for FDL outlined by providers and its approaches. 


\section{Understanding the Use of FDL Through Users' Perspectives: Focus Groups}

In order to introduce the perspectives of potential FDL learners, four focus groups, involving in total 39 individuals, were conducted in between August and October 2016 in four different countries. All participants gave their informed consent previously to their participation in the focus group interviews. The focus groups all had different profile: Sweden focused on newly-arrived refugees who were still in a reception camp, Cyprus focused on migrants and refugees who had been in the country typically over five years, Belgium focused on migrants who were participating in an obligatory Belgian integration course, and Germany focused on newly-arrived refugees with higher education backgrounds. The choice of location for the focus groups was based on an assessment of the critical mass of migrant/refugees in the countries, the different immigration policies the countries may employ, and the relative geographic and linguistic diversity. One group was dedicated to higher education due to the many current initiatives in this field found by the literature review.

The 39 refugees and migrants who participated in the focus groups came from nine different countries: Afghanistan, Bangladesh, Ghana, India, Iran, Morocco, Palestine, Somalia, and Syria, and were between 19 and 55 years old. Twenty-four of them had been enrolled in higher education in their home countries and 18 had a 3 -year or longer academic degree. None of the participants in the focus groups had been in refugee camps outside Europe. In the Swedish and the German focus groups, all participants ( 17 in total - three females) were refugees. The Cyprian and Belgium groups were mixed: 12 participants (11 females) were migrants (as opposed to those with refugee status). The refugees who participated were predominantly male, in their 20s, and had a tertiary education background, whereas the migrants who participated were largely women, over 30 , with no tertiary education.

The focus groups were semi-structured. Questions about awareness, level of use of FDL, and perceptions (perceived barriers, advantages and disadvantages, and priorities in terms of learning purposes) were included (See Appendix A). In order to guarantee validity and reliability, the topics and questions were discussed by experts on ICT in education and migration studies, which were part of the research consortium. The groups used Arabic, English, and/or the local host country language. In the interests of encouraging the participants to be open and uninhibited, discussions were not recorded but notes were taken. So as to guarantee adequacy and reduce possible bias, notes were taken by two different persons in each focus group and triangulated in the codification done after the focus group.

\section{Understanding the Use of FDL Through Providers Perspectives: Semi-Structured Interviews}

In order to supplement the perspectives of learners/beneficiaries with those of the designers, developers, and managers of FDL initiatives, telephone interviews were held with representatives from 10 different FDL initiatives, including CEOs, founders, partners, and those in charge of business development, academic/content development, and research. The interviews were semi-structured and included guiding questions about their philosophy and creation, approach, the challenges they face, their business models, and the advice that the interviewees would give to others in the field (See Appendix B). In the same way as for the focus groups, informed consent was provided by interviewees, the questions were internally validated by experts and, although not recorded, notes were taken by two different members of the research team and triangulated in the codification phase.

The chosen initiatives were: Edraak, Funzi, Information Sweden, InZone, Jamiya Project, KIRON Open Higher Education, Language, Academic Skills and E-learning Resources (LASER), Meeting the 
Health Literacy Needs of Immigrant Population (MEET), Ready for Study, and Welcomm!. The initiatives vary in how long they had been running, nature, type of FDL employed, approach, business model, and target group within the refugee/migrant population. It should be noted that the majority targeted higher education, which reflects a current focus in this sector. Six initiatives specifically target higher education students and/or students in refugee camps (Edraak, InZone, Jamiya, Kiron, LASER, and Ready for Study), and four target adults, notably for civic integration and language learning (Information Sweden, MEET, WELCOMM!, and Funzi). Funzi, providing mobile learning, aims to provide mobile learning for civic integration and employment, while the Information Sweden initiative is a stand-alone platform which aggregates FDL resources for civic integration and language training. Two initiatives (MEET, WELCOMM!) have piloted FDL resources (including training on how to use them), which are now available as Open Educational Resources for reuse in other contexts.

The selection demonstrated the variety and richness of the chosen initiatives, which, together with complementary data from the catalogue of initiatives, allowed us to obtain information about the approaches they take, their development trajectory, and how they work with and assess potential migrant refugee learners and their needs.

\section{Analysis}

Thematic analysis was used for the data analysis. The data obtained through interviews with the FDL initiative representatives and focus groups was categorized in three broad topics that reflect our research question:

- Offer and Approaches: Quantity, types, and strategies developed by initiatives in order to effectively deliver FDL.

- Awareness and Take up: Understanding and degree of knowledge about FDL by migrants and refugees.

- Perception by Migrants and Refugees: How learners/potential learners perceive the potential of FDL for inclusion, integration, and further learning.

Following a semi-structured approach, we combined a top-down approximation with a bottom-up one. Although some sub-topics were defined by the research team (e.g., perception of barriers, advantages, and disadvantages), the analysis tried to capture the vision of the interviewees and participants in the focus groups in an open way. Consequently, sometimes different and not comparable sub-areas of interest emerged for each of the three types of FDL analysed. The section below summarizes the main results of the analysis and serves as a summary for the topics that emerged. 


\section{Results}

\section{Technical Issues}

An important precondition for the up-take of FDL resources is that they can be accessed and used anywhere (Moser-Mercer, 2014). Migrant, refugees, and providers confirmed that a stable Internet connection is a natural priority for participating in FDL, but it is not always guaranteed in the case of migrants and refugees, especially when they are in transition phases or refugee camps. As a consequence, the possibility of implementing of mechanisms of circumventing connectivity issues, (for example, FDL provision offline and m-learning, and the use of simple graphic designs, no-frills apps, and applications that can work with low bandwidth) were highly recommended and valued by learners.

\section{Understanding of FDL and Take-Up}

In general, the focus group interviews indicated that migrants and refugees lack general information on, and awareness of, what FDL are being offered. In addition, in all four focus groups (but especially the ones in Sweden, Brussels, and Nicosia), there was an initial reluctance to understand and embrace FDL, which could be partly due to unfamiliarity with digital learning, or to the fact that FDL offers may not be provided in their first language. However, as the focus group interviewed progressed, a broader understanding of the concept emerged, the participants began to reflect on how FDL, and how more generally flexible educational provision, could support inclusion and integration. A participant in the Berlin focus group stated this as follows, "as (a) student in an online education program or course, you have more authority and you can be more active. The flexibility to repeat and access the educational material is positive."

Social media was the most well-known, best understood, and most frequently used FDL channel by refugees, particularly the different Facebook groups that target refugees at different stages of their migration process. Facebook and other social media groups are not strictly within the definition of FDL used for Moocs4Inclusion project, but were considered by the participants as an important resource.

\section{FDL Purposes}

While Moocs4Inclusion project attempts to generally categorize the FDL initiatives identified through the project into different learning purposes, some FDLs overlap and have double purposes. For example, it was found that initiatives for language learning often co-target civic integration and viceversa. Civic and integration and employment-related initiatives were also found to be often directly connected, even though some employment-related initiatives are more like job portals and offer transversal skills for employment while civic integration initiatives help migrants and refugees with administrative and legal hurdles when they arrive in a country.

Our analysis indicates that there are more similarities than differences between the purposes of FDL initiatives, irrespective of the target group. The following sections summarises some of the specific issues related to the three different purposes for FDL for refugees and migrants, as identified by this study.

\section{FDL for Language Learning}

Offer and approaches. Language-related FDL tends to have a dual focus on language skills for migrants as an introduction to living in the host society, and on civic integration (Information 
Sweden, Welcomm!, and MEET). It can also provide a pre-qualification for participating in higher education (Ready for Study, LASER).

Compared with the two other fields, there is abundance of resources for FDL language learning and of media. The existence of many current FDL initiatives in this field, as well as digital materials that can be reused and/or adapted, has been identified as an opportunity. In first instance, learners can participate in this kind of learning more easily because of the availability of mobile phones (although not always necessary to have an internet connection) and a plethora of translation apps, other commercial mobile apps (such as Duolingo or Babbel), or educational videos (e.g., YouTube). In addition, providers can use or readapt many Open Educational Resources (OER), MOOCs, and university language courses to provide free digital language learning for migrants and refugees.

Besides using translators, commercial mobile applications, and re-appropriating online language courses, providers are also experimenting with more innovative approaches. One approach to free digital language learning is the creation of innovative learning materials that can be used online, offline, or in face-to-face classes. For example, Welcomm! aims to encourage migrant children and families to learn a language by creating learning materials linked to their own world - family, kids games, sports, arts, etc. - and by promoting non-formal learning. MEET is another example of an EU project that provides innovative digital resources, in this case to teach health vocabulary.

A first step of integration for migrants and refugees is to learn their host country's language in order to be able to participate, not only in society and the labour market, but also in other digital or face-toface learning activities. Upon arrival, many migrants and refugees are not able to understand or speak the local language or English. In order to address this problem, several initiatives are offering a Content and Language Integrated Learning (CLIL) approach (Coyle, 2007) that facilitates language learning through the acquisition of relevant content that can enhance (e.g., civic integration, employability, or higher education).

In higher education, some initiatives have incorporated language learning programmes either as a parallel track or added service, or as integral to the higher education offer. Some use and promote the plethora of existing language apps. Others develop their own language services in a blended learning model. Kiron has developed a Language School that offers students a selection of online and offline courses. ReadyforStudy, uses the CLIL approach and builds on the MOOC concept. It targets refugee students who want to apply to German universities and combines language learning with social and practical competencies regarding accessing and succeeding in the German HE system. LASER, an initiative that targets displaced students in Jordan, Syria, and Lebanon, takes a three-pronged blended learning approach: face-to-face language courses facilitated online, access to accredited higher education distance learning through the Open University and Amity University, and language and academic skills training delivered in Syria by a partner organisation (SPARK). This varied offer caters for the needs of different refugees in different settings, and is also directly linked to eventually accessing higher education degrees.

Awareness and take up: Despite the general lack of knowledge about FDL, among the refugees (as opposed to the migrants present in the groups), language apps were well-known and were found particularly useful for translation. The use of other language apps (targeted towards refugees and including language tests) varied greatly; no clear pattern was discernible except that they were used more frequently by younger refugees with a tertiary degree. Participants in focus groups were 
generally reluctant to pay for advanced versions of language apps. When these functionalities are not for free, they may be underused by migrants and refugees.

Migrants' and refugees' perceptions: All the refugees and migrants who participated in focus groups agreed that their top priority was to learn the language of the host country and/or learn or improve their knowledge of English. This priority was further accentuated in relation to (civic) integration/inclusion, employment, and further education - especially for the younger refugees. In general, language was considered to be a means of overcoming the challenges that the practicalities of life in a new country pose.

FDL for language learning was also perceived as a way of starting to learn the local language before arriving in the host country (e.g., while refugees are in camps, fleeing, waiting for asylum, or while future migrants are still in their countries of origin). The participants in the focus groups found that they needed to start language learning as early as possible and while still applying for asylum.

FDL that is used in a blended learning approach was generally more valued. The focus groups made it clear that language FDL is ideally a complement to practicing the new language with other individuals. The participants found that face-to-face teaching yields better outcomes than stand-alone online language training. They also valued engaging with other students, learning from others' oral mistakes, and being physically present in a classroom environment. That said, they found that FDL resources (through mobile apps) offer a readily available tool that can enhance their vocabulary base and reinforce the basics of grammar. It was stated by a participant in the Swedish focus group as follows:

We can learn from apps, but we need contact to real people. We can learn the grammar, but we need to learn how to string sentences together. We have to talk to real people for us to be integrated into "real life."

\section{FDL for Civic Integration and Employment}

Offer and approaches: FDL initiatives that aim to enhance the civic integration and employment for refugees and migrants use diverse technologies: platforms (Information Sweden), apps, YouTube, videos, mobile learning (Funzi), and online tool kits/learning resources (MEET). They can be standalone or supplement face-to-face skills training. They can serve as information/reference points, be a way of testing or presenting existing knowledge, or certifying the knowledge acquired. The knowledge provided through these initiatives typically covers civic rights, legal knowledge for asylum seekers, housing, health insurance, education, etc., but also "softer" information on how to meet locals, how to apply for employment, and what different employment sectors demand from employees. Other FDL initiatives provide information on the history and the culture of the host country and can also be utilised in face-to-face integration courses.

These initiatives often have elements of the CLIL approach (see FDL languages) and do not generally lead to certification. However, there is one exception among the initiatives studied: Funzi, which uses mobile learning as its platform and is easily adaptable when it comes to content, currently provides civic integration training and information to refugees in the Nordic countries. It also collaborates with local partners, primarily in Africa and Asia, to deliver short skills courses for employment. The latter type of FDL has a clearly (non-formal) educational scope and can provide certification (badge) for a fee, often paid by an employer at this stage. 
Another example of a platform that targets civic integration is Information Sweden, which aggregates a host of different FDL initiatives in nine different languages, quality assures the content, and provides a wider selection of FDL for civic integration, employment, and language training.

Awareness and take up: The focus group participants generally had little knowledge and understanding of FDL for civic integration and employment, except for the refugees with higher education experience in the Berlin group. Here, all the group participants used social media and Facebook groups that provide information relevant to their situation and the country that they are in. Others pointed to LinkedIn. While this is not strictly within the definition of an FDL, it can be seen as providing peer-learning, and as an important platform for FDL initiatives with a civic integration/employability purpose to reach their target group.

Perception by migrants and refugees: Focus group participants were least aware of FDL for civic integration and employment and therefore generally found this type of training difficult to relate to. When asked how they would integrate, focus group participants pointed out that a digital tool cannot, in itself, provide social integration or contact with an employer. As such, these tools were considered "exclusionary" rather than "inclusionary." As with learning a language, participants in the focus groups generally agreed that it is necessary to meet physically (with locals, employers, officials, or other refugees and migrants) in order to exchange experiences and ask questions when they had difficulty understanding certain concepts or regulations that could affect their inclusion and settlement. Meeting face-to-face was also perceived as a chance to establish a social network. Thus, they made the case for FDL for civic integration, in particular, to be part of a blended learning activity. Regarding employment, the participants stressed their need to create new networks, though they valued the apps and platforms. Refugees in Berlin brought up the example of the German App SINGA, which matches German volunteers with individual refugees as "friends or mentors." These volunteers can then, if necessary, guide and help the refugee towards civic integration. Other examples are apps developed by refugees for refugees that can be defined as train-the-trainers/ "peer-education" models, where refugees and migrants can use FDL for teaching each other in the community. Finally, in many cases, the certification from online courses was perceived as less useful in the labour market, though none of the participants had experience with this: "traditional education certificates are still more likely to guarantee obtaining the job.”

\section{FDL for Higher Education}

Offer and approaches. Most of the new comprehensive FDL initiatives (as opposed to apps or individual FDL resources) are for formal education/degree purposes, most specifically higher education. Most of the larger scale FDL initiatives for migrants/refugees identified through the Moocs4Inclusion project have taken place in this area (six out of the 10 initiatives studied focused on higher education, including Kiron, Jamiya, Edraak, InZone, LASER, and Ready for Study).

In terms of content, initiatives vary between developing new content (like Jamiya, which delivers original MOOCs in Arabic, based on existing university courses) and re-purposing digital/online course content through cooperation with universities and MOOC platforms (Kiron). The cost implications of these different approaches are being closely studied, especially as many initiatives are donor-driven or crowd-funded and are struggling with their present cost models. In general, blended and facilitated models cost more, though it is agreed that they have more impact. 
The HE initiative representatives interviewed concurred that it was essential to provide higher education opportunities to migrants/refugees, in order to a) enable them to work and integrate into their host societies, and b) to ensure that their skills and qualifications remain relevant, should they be able to return to their home countries. However, diverse approaches were being employed in this sector. All the initiatives were in the process of re-conceiving and developing different models for FDL in higher education that could be scaled up to reach a greater number of refugees in camps, in neighbouring countries, and in further host countries. All professed to be experimenting with these models and to be continuously receiving feedback from their students and the partners that they work with. Most participated in collaborative models made up of HE providers, ICT developers and tech start-ups, social workers (particularly in the camp context), local and federal government funders, other international organisations and, most importantly, the students themselves.

Several initiatives aim to help students with the transition from their "displaced" status into the formal higher education sector. Though the refugees are perceived as ordinary students, they are also seen as vulnerable and thus they have a need for more time, student support services, mentors, and knowledge about studying in a new and (unfamiliar) environment. As a result, the HE initiatives prefer the blended and facilitated approach. Kiron, for example, offers a 2-year online course to refugees (including those that do not yet have their formal paperwork in order or proof of prior learning), followed by entry into a partner university to complete the degree in situ. InZone combines on-site and virtual learning with support and mentoring in refugee camps outside Europe.

The research also demonstrated that European universities are interested in enrolling and engaging with refugees. Some see the recent refugee crisis as an opportunity for internationalising their campuses (the University of Oslo, for example, is leading a new EU project called Academic Refugee and has opened its language learning resources internationally to refugees). According to representatives of Kiron and Jamiya, many universities are keen to collaborate with FDL initiatives for refugees, though they confess that resources for developing FDL, and specifically MOOCs, are still lacking. In addition, problems regarding recognition of FDL studies remain. In this respect, there is a strong movement towards utilising Bologna Tools (ECTS, learning agreements) for FDL course content and seeking accreditation in respective European education systems. InZone, Kiron, LASER and Jamiya are committed to working with ECTS, for example, and Kiron and InZone in particular, employs learning agreements with universities for the recognition of FDL as prior learning up to the amount of 60 ECTS.

A transversal concern with regards to the accessibility of higher education FDL for migrants and refugees is the language of delivery of the FDL offer. Most of the higher education initiatives studied are incorporating language support into their offer. Jamiya and Edraak have based their offer on the premise that more high quality FDL is needed in Arabic: "There is a scarcity of Arabic learning content online and this is a huge challenge; Less than $3 \%$ of digital content globally is in Arabic and this $3 \%$ is debatable in terms of quality." Jamiya believes that by using Arab scholars to teach most of the course in Arabic, Syrian students will benefit from culturally sensitive teaching, adapted to and applicable in a European context. FDL in Arabic/native languages are thus an important component of the general FDL panorama.

Awareness and take up. Several of the representatives of initiatives interviewed stressed that the take up of FDL was generally greater by migrants/refugees with higher education, due to higher digital literacy and general motivation to learn, who needed to continue interrupted higher education studies 
and/or upgrade their existing qualifications. That said, higher education was deemed to be secondary to language learning and civic integration, which were (or had been) transversal needs for all refugees/migrants that participated in focus groups.

Perception by migrants and refugees. Blended learning approaches with support structures seemed to be unanimously preferred for higher education delivery, for many of the reasons that these are also preferred for civic integration and language learning. These approaches are often delivered in partnership with established higher education institutions (HEI).

Obtaining credits and eventually a recognised, accredited degree, is considered both a desired outcome and a challenge for these initiatives: in words of a participant in our research "Bologna Process tools are absolutely useful in the FDL context." This is an additional motive for working with existing higher education institutions. Kiron works closely with partner universities that have committed to recognizing modules from the MOOC-based courses that the students take online. Jamiya has worked with the University of Gothenburg to adapt existing programmes, deliver them in Arabic and subsequently gain recognition in the Swedish system. InZone is backed by the University of Geneva, and provides certification through the university.

\section{Discussion and Conclusions}

The analysis presented above was based on information from focus groups with 39 refugees and migrants and interviews with 24 representatives from 10 different FDL initiatives. When disaggregating available FDL by learning purpose, we found that there are not many differences regarding the basic principles, though some specificities can be found. Although our analysis is not based on a comprehensive sample of initiatives for migrant and refugees in all situations, a wide range was covered (and collected in the catalogue from which this current sample was collected). Thus, some conclusions and recommendations for developing and exploiting FDL in Europe can be derived from the research. It should be noted that the field is a moving target, as more initiatives and FDL resources are emerging almost daily, and more studies are being commissioned to assess the potential of FDL for users.

\section{Transversal Conclusions and Recommendations}

The results of the interviews with representatives from the initiatives and the focus groups with migrants and refugees confirm the results from previous literature (De Waard et al., 2014; Lewis \& Thacker, 2016; Mason \& Buchmann, 2016): the use of a personalized and guided pedagogical approach is one of the main success factors. FDL as teaching material for migrant or refugee education can be an adequate tool, if a context and culturally-sensitive approach is used. Migrant/refugee learners are a fragile target group with needs that go beyond simply providing learning content and information. All focus groups participants, irrespective of age or of the type of FDL in question, agreed that face-to-face contact in the learning process would be ideal, and saw FDL as a (potential) compliment. One hundred percent of online learning is considered exclusionary since is does not allow refugees and migrants to build social networks via face to face contacts with local people or others in similar situations. A blended and guided format with facilitators, mentors, student support, and career services was considered important for the success of the FDL. This is especially true for those FDL that aim to achieve civic integration or access to higher education. Adaptive learning technologies aim to customize content and learners' paths (Somyürek, 2015) and evidence 
shows that these approaches could contribute to better outcomes (Escueta, Quan, Nickow \& Orepoulos, 2017). All in all, research indicates that guided and personalized approaches that respond to specific cultural/context sensitivities, and mix face-to-face with digital learning are adequate for the success of FDL for migrants and refugees.

Refugees and migrants generally are not familiar with FDL that targets them directly as a group. However, the majority of refugees and migrants are familiar with using a mobile phone, translation applications, and social media. The group that is most familiar with FDL is that of young refugees with a higher education degree or part of a degree. In addition, when FDL is explained to migrants and refugees, they seem to value the flexibility of learning that it offers. The possibility of FDL to target individuals who are not able to access other types of education due to lack of formal documentation of prior learning, low availability of education or regulatory barriers for entry is considered a strength. It was also suggested that FDL offers should be promoted to migrants and refugees before they arrive in their host country, so as the facilitate uptake upon arrival. A clear strategy for communicating FDL initiatives to learners, funders, partners, and the general public is critical for awareness rising. Consistent with previous literature (Reichel, Siegel, Andreo, Carrettero Gomez, \& Centeno Mediavilla, 2015), our results show that the use of social media is high among migrants and refugees and hence it could be a good instrument for both promoting FDL offers and also surveying the needs of the changing migrant/refugee learning population.

\section{Specific Conclusions and Recommendations}

FDL that aims to provide or facilitate access to higher education has some specific characteristics. First, it was found to be very important to assess the prior language and academic knowledge of learners. This was regarded as important for ensuring the students' success. Secondly, although accreditation and certification is a key issue for nearly all learners and FDL initiatives (with the exception of the more informal types of learning for civic integration and employment), it is particularly important for higher education students. Therefore, the use of the Bologna Process architecture (recognition, quality assurance, and qualification frameworks) and transparency tools (learning agreements, learning outcomes, and ECTS) are considered helpful by initiative designers when it comes to the recognition of FDL initiatives and in aligning them to the labour market and the European Higher Education Area (EHEA).

Language is considered a transversal success factor in education (EURYDICE, 2009; Rangvid, 2007), which has also been found to be true for FDL. Language learning was a transversal component of all the initiatives studied, whether as an objective in itself, a means for employment or civic integration or as a compliment/added service in obtaining a HE degree. The provision of FDL for language learning was found to depend very much on, a) the location of the target group, and b) the purpose of the training. While language apps and google translate are the more popular FDL tools among migrants and refugees, they are seen more as a compliment to face-to-face and/or facilitated language learning, which is considered more desirable.

Finally, regarding the use of FDL for civic integration and employment, it is worth highlighting that the recognition of FDL by employers is a key issue (Witthaus et al., 2016) and according to the participants in the focus groups, it may have an impact on the employability of migrants and refugees. According to the perception of the FDL providers and learners, the use of recognition systems that are accepted by employers, and ideally developed in partnership with them, could be a valuable solution and facilitate the uptake of FDL by migrants and refugees. 


\section{References}

Calvó-Armengol, A., Patacchini, E., \& Zenou, Y. (2008). Peer effects and social networks in education. IZA Discussion Paper Series, 3859. Retrieved from: http://ftp.iza.org/dp3859.pdf

Castaño Muñoz, J., Duart, J., \& Sancho-Vinuesa, T. (2013). The Internet in face-to-face higher education: Can interactive learning improve academic achievement? British Journal of Educational Technology, 45(1), 149-159. doi: 10.1111/bjet.12007

Castaño Muñoz, J., Kreijns, K., Kalz, M., \& Punie, Y. (2017). Does digital competence and occupational setting influence MOOC participation? Evidence from a cross-course survey. Journal of Computing in Higher Education, 29(1), 28-46. doi: 10.1007/s12528-016-9123-Z

Colucci, E., Smidt, H., Devaux, A., Vrasidas, C., Safarjalani, M., \& Castaño Muñoz, J. (2017). Free digital learning opportunities for migrants and refugees. An Analysis of current initiatives and recommendations for their further use. JRC Science for Policy Report. Luxemburg: Publications Office of the European Union. doi: 10.2760/684414

Coyle, D. (2007). Content and language integrated learning: Towards a connected research agenda for CLIL pedagogies. International Journal of Bilingual Education and Bilingualism, 10(5), 543562. doi: $10.2167 /$ beb459.0

Dahya, N. (2016). Education in conflict and crisis: How can technology make a difference? A landscape review. Bonn, Germany: Deutsche Gesellschaf für Internationale Zusammenarbeit (GIZ) GmbH. Retrieved from http://wvi.org/sites/default/files/20160303 Landscape Review ICT4E in Conflict and Crisis.pdf

De Paola, M., \& Brunello, G. (2016): Education as a tool for the economic integration of migrants. EENEE Analytical Report Series, 27. doi: 10.2766/46295

De Waard, I., Gallagher, M., Zelezny-Green, R., Czerniewicz, L., Downes, S., Kukulska-Hulme, A., \& Willems, J. (2014). Challenges for conceptualising EU MOOC for vulnerable learner groups. In U. Cress \& C. Delgado Kloos (Eds.), Proceedings of the second European MOOC Stakeholder Summit (pp. 33-42). Lausanne, Switzerland: EMOOCs. Retrieved from: https://www.emoocs2014.eu/sites/default/files/Proceedings-Moocs-Summit-2014.pdf

Escueta, M., Quan, V., Nickow, J., \& Orepoulos, P. (2017). Education technology: an evidence-based research. NBER Working paper Series, 23744. doi: 10.3386/w23744

European Commission. (2016a). Analytical underpinning for a New Skills Agenda for Europe (SWD(2016) 195 final). Retrieved from: http://eurlex.europa.eu/resource.html?uri=cellar:cdofa1ca-2eeg-11e6-b497o1aa75ed71a1.0001.02/DOC 1\&format=PDF

European Commission. (2016b). Communication from the commission to the european parliament, the council, the European economica and social committee and the committee of the regions: Lives in dignity: From aid-dependence to self-reliance (COM(2016) 234 final). Retrieved 
from http://ec.europa.eu/echo/files/policies/refugees-

idp/Communication Forced Displacement Development 2016.pdf

Eurostat. (2016). Migrant integration statistics-education. Retrieved from

http://ec.europa.eu/eurostat/statistics-

explained/index.php/Migrant integration statistics - education

Eurostat. (2017). Asylum statistics. Retrieved from http://ec.europa.eu/eurostat/statisticsexplained/index.php/Asylum statistics

EURYDICE. (2009). Integrating immigrant children into schools in Europe. Brussels: European Commission- Education, Audiovisual and Culture Executive Agency. Retrieved from http://eacea.ec.europa.eu/education/eurydice/documents/thematic reports/101EN.pdf

Glass, C. R., Shiokawa-Baklan, M. S., \& Saltarelli, A. J. (2016). Who takes MOOCs? New directions for Institutional Research, 167, 41-55. doi: 10.1002/ir.20153

Jansen, R.S., van Leeuwen, A., Janssen, J. Kester, K, \& Kalz, M. (2017). Validation of the selfregulated online learning questionnaire. Journal of Computing in Higher Education, 29(6), 6-27. doi: 10.1007/s12528-016-9125-x

Kahanec, M., \& Mendila, M. (2007). Social determinants of labor market status of ethnic minorities in Britain. IZA Discussion Paper Series, 3146. Retrieved from http://ftp.iza.org/dp3146.pdf

Lewis, K., \& Thacker, S. (2016). ICT and the education of refugees: A stocktaking of innovative approaches in the MENA region (SABER-ICT Technical Paper Series, 17). Washington, D.C.: World Bank. Retrieved from http://documents.worldbank.org/curated/en/455391472116348902/pdf/107997-WPP160311-PUBLIC-ICT-and-the-Education-of-Refugees-final.pdf

Liyanagunawardena, T. R., Adams, A. A., \& Williams, S. A. (2013). MOOCs: A systematic study of the published literature 2008-2012. The International Review of Research in Open and Distributed Learning, 14(3), 202-227. doi: 10.19173/irrodl.v14i3.1455

Mason, B., \& Buchmann, D. (2016). ICT4Refugees - A report on the emerging landscape of digital responses to the refugee crisis. Bonn and Eschborn, Germany: Deutsche Gesellschaf für Internationale Zusammenarbeit (GIZ) GmbH. Retrieved from https://regasus.de/online/datastore?epk=74D5roYc\&file=image 8 en

Moser-Mercer, B. (2014). MOOCs in fragile contexts. In U. Cress \& C. Delgado Kloos (Eds.), Proceedings of the second European MOOC Stakeholder Summit (pp. 114-121). Lausanne, Switzerland: EMOOCs. Retrieved from http://www.unige.ch/inzone/files/9514/8965/4778/MOOCsinFragileContexts.pdf

Moser-Mercer, B., Hayba, E. \& Goldsmith, J. (2016). Higher education spaces and protracted displacement: How learner-centered pedagogies and human-centered design can unleash refugee innovation. Paper for 2016 UNESCO Chair Conference on Technologies for Development: From Innovation to Social Impact (Tech4Dev Conference), Lausanne, 
Switzerland 2-4 May 2016. Retrieved from http://cooperation.epfl.ch/files/content/sites/cooperation/files/Tech4Dev\%202016/1216Moser-Mercer-SE03-HUM Full\%20Paper.pdf

Nonchev, A., \& Tagarov, N. (Eds.). (2012). Integrating refugee and asylum-seeking children in the educational systems of EU member states: Evaluation and promotion of current best practices. Sofia, Bulgaria: Centre for the Study of Democracy. Retrieved from http://www.csd.bg/fileadmin/user upload/INTEGRACE handbook.pdf

Organisation for Economic Co-operation and Development. (2015). Immigrant students at school easing the journey towards integration. Paris, France: OECD Publishing. doi: 10.1787/9789264249509-en

Pane, J. F., Steiner, E. D., Baird, M. D., Hamilton, L. S., \& Pane, J. D (2017). Informing progress: Insights on personalized learning implementation and effects. Santa Monica, CA: RAND Corporation. Retrieved from https://www.rand.org/pubs/research reports/RR2042.html

Poros, M. V. (2008). A social networks approach to migrant mobilization in Southern Europe. American Behavioral Scientist, 51(11), 1611-1626. doi: 10.1177/0002764208316360

Rangvid, B. S. (2007). Sources of immigrants' underachievement. Education Economics, 15(3): 293326. doi: 10.1080/09645290701273558

Reichel D., Siegel M., Andreo J.C., Carrettero Gomez S., \& Centeno Mediavilla, I.C. (2015). ICT for the employability and integration of immigrants in the European Union: A Qualitative Analysis of a Survey in Bulgaria, the Netherlands and Spain. JRC Science and Policy Report. Seville, Spain: Joint Research Centre of the European Commission. doi: 10.2791/48198

Rovai, A.P (2002). Sense of community, perceived cognitive learning, and persistence in asynchronous learning networks. The Internet and Higher Education, 5(4), 319-332. doi: 10.1016/S1096-7516(02)o0130-6

Save the Children. (2017, May 23). Child refugees in Greece have been out of school for an average of 1.5 years (Blog post). Retrieved from https://www.savethechildren.net/article/childrefugees-greece-have-been-out-school-average-15-years

Schneeweis, N. (2011). Educational institutions and the integration of migrants. Journal of Population Economics, 24, 1281-1308. doi: 10.1007/s00148-009-0271-6

Somyürek, S. (2015). The new trends in adaptive educational hypermedia systems. International Review of Research in Open and Distributed Learning, 16(1). doi: 10.19173/irrodl.v16i1.1946

Song, L., \& Hill, J. R. (2007). A conceptual model for understanding self-directed learning in online environments. Journal of Interactive Online Learning, 6(1), 27-42. Retrieved from http://www.ncolr.org/jiol/issues/pdf/6.1.3.pdf 
Toven-Lindsey, B, Rhoads, R. A, \& Berdan Lozan, J. (2015). Virtually unlimited classrooms:

Pedagogical practices in massive open online courses. The internet and Higher Education, 24, 1-12. doi: 10.1016/j.iheduc.2014.07.001

The United Nations Higher Commissioner for Refugees. (2016). Missing out: Refugee education in crisis. Geneva: Author. Retrieved from http://www.unhcr.org/57dgdo1do

Witthaus, G., Inamorato dos Santos. A., Childs, M., Tannhäuser, A., Conole, G., Nkuyubwatsi, B., \& Punie, Y. (2016). Validation of non-formal MOOC-based Learning: An analysis of assessment and recognition practices in Europe (OpenCred). Luxemburg: Publications Office of the European Union. doi:10.2791/809371 


\section{Appendix A}

\section{Focus Groups Common Guide}

- In your country of origin context, is it common to take part in digital learning? Are you familiar with Digital learning?

- Do you think (free) digital learning can help you prepare for your integration, future employment, language/cultural preparation, keeping up your skills and knowledge?

- If yes, which digital learning initiatives do you think could enhance integration and inclusion: language, cultural courses, civic education courses, academic courses/skills-development/upgrading courses, re-training, formal courses/education?

- If yes, at what stage would they be most useful? Why were you interested in these digital learning tools and initiatives (for which purpose)? (if previous experience)

- Which digital learning initiatives (apps, videos, learning platforms, MOOCs) would you liked to have while awaiting asylum? Why?

- What are the opportunities and what are the challenges for the encountered/aspirational digital learning initiatives?

- What are the barriers: physical (availability of "equipment”), language, time, legal, financial, family?

- Do the initiatives need to be targeted specifically at you (and how)? That is to say, would you need extra support in accessing and using these digital learning offers, even if they are open and free? 


\section{Appendix B}

\section{Interview Guide}

1- Origin and Development

- What has been the inspiration for this initiative and what did you want to achieve? If you are a partner of this initiative (and not a founder), why did you get involved?

- Who are the partners? How did you identify your partners?

- Who commissioned this initiative? Who pays/paid for it/the development of it? Who has been involved in its development? Which stakeholders have been consulted for its development and how?

- What is the mission? What is the core target group? Objectives?

- What is the business model? What were the start-up costs? What are the intentions for longer-term financing?

- What type of initiative is it? A MOOC or MOOC platform? On-line and blended learning? An App? A combination? What is the specific approach and/or pedagogy used?

- What type of technology is used? Why was this elected?

- When did this initiative start? Is it a one-off or does it have a longevity goal?

- Do you feel like you have a good perspective on similar initiatives in the field and how to coordinate with other initiatives? Have you taken practices from/been inspired by other initiatives?

\section{2- Access and Recognition}

- What are the prerequisites for access (open, free, limited to certain groups)?

- Has it been developed in collaboration with the target population? How has it been promoted to the target population?

- Recognition of learning outcomes (if relevant) - How is this done? Are there problems certification, accreditation, etc.?

\section{3- Monitoring and Sustainability}

- What are the aspirations for sustainability and further development? Could it be spread or upscaled?

- What kind of QA procedures have been developed for the initiative? Are there concrete monitoring plans?

- Are effects and impact measured? Is this public information? Are the statistics on impact that are not yet public and can they be shared?

- If not, are you planning impact assessment and how? What is the planned approach?

- Do you have data on participation or do you have plans to collect it?

- If you are not assessing impact or tracking participation would you like to participate in an impact assessment study in the future? Would you be interested in a European research project of this nature?

4- Challenges and Recommendations 
- Are there conclusions regarding the challenges and/or encountered problems? What, in your opinion, is the main challenge?

- Do you think FDL is the best option for migrants and refugees? Why? Or rather, is it a better option for certain/specific targets in the migrant/refugee population and why? In what format?

- How can policy makers support the integration of migrants and refugees via FDL? What would you ask of your policy makers in order to better support your initiatives or similar initiatives, to guarantee success and impact?

- Would it be possible to talk to someone who has participated in the initiative (a student)?

i The views expressed in this article are purely those of the authors and should not be regarded as stating an official position of the European Commission.

Athabasca

University

(c) (†) 